\title{
Allergic rhinitis, rhinoconjunctivitis and hayfever symptoms among children are associated with frequency of truck traffic near residences: a cross sectional study
}

\author{
Joyce Shirinde ${ }^{1 *+}$, Janine Wichmann ${ }^{2+}$ and Kuku Voyi ${ }^{2+}$
}

\begin{abstract}
Background: Allergic rhinitis (AR) is an increasing and common condition affecting many people globally, especially children. The aim of the study was to investigate the association between the frequency of truck traffic and allergic rhinitis symptoms, rhinoconjunctivitis and hayfever among 13 to 14 year old school children in Ekurhuleni Metropolitan Municipality, Gauteng Province, South Africa.

Methods: In a cross-sectional study design, 3764 children from 16 randomly selected high schools were eligible to participate, 3468 completed the International Study of Asthma and Allergies in Childhood (ISAAC) Phase I questionnaire of which 3424 were suitable for analysis; the overall response rate was $92 \%$. Data were analysed using multilevel logistic regression analysis.

Results: The prevalence of self-reported rhinitis ever, current rhinitis rhinoconjunctivitis and hayfever was 52, 40, 21 and $37 \%$ respectively. Rhinitis ever, current rhinitis and current rhinoconjunctivitis were significantly associated with the frequency of trucks passing near residences almost all day on weekdays, (OR $1.4695 \%$ Cl: 1.16-1.84), (OR $1.6095 \%$ Cl: 1.24-2.02) and (OR $1.4295 \%$ Cl: 1.09-1.84) respectively. No association was observed between truck traffic and hay fever in the multiple analyses.

Conclusion: The study shows a high prevalence of allergic rhinitis symptoms amongst children. The results support the hypothesis that traffic related pollution plays a role in the prevalence of allergic rhinitis symptoms in children residing in the area.
\end{abstract}

Keywords: Allergic rhinitis, Rhinoconjunctivitis, Hayfever, Traffic, Air pollution, South Africa

\section{Background}

Allergic rhinitis (AR) is a global health problem, affecting many people from childhood to adulthood [1]. The disease is most common and one of the leading chronic conditions in children less than 18 years of age; it is frequently ignored, under-diagnosed, misdiagnosed or mistreated $[2,3]$. Rhinitis is defined as the inflammation of the nasal lining, but is characterised by nasal symptoms of: sneezing, itching, rhinorrhoea/nasal running and/or nasal congestion [4]. Rhinitis is frequently accompanied

\footnotetext{
*Correspondence: shirindej@tut.ac.za

${ }^{\dagger}$ Equal contributors

${ }^{1}$ Department of Environmental Health, Tshwane University of Technology, Private Bag X680, Pretoria 0001, South Africa

Full list of author information is available at the end of the article
}

by symptoms involving the eyes, ears and throat, including postnasal drainage $[2,4]$. The disease affects 400 million people worldwide, with high prevalence recorded in industrialised nations. Epidemiological surveys have reported an increase in the disease, with different regions of the world reporting prevalence rates of between 10 and $40 \%$. The prevalence of childhood AR shows wide global variation, ranging from 0.8 to $39.7 \%$ [5-10].

The reasons for the global increase in the prevalence of allergic rhinitis are still not understood. The disease has been associated with various risk factors including among others: gender, housing characteristics, socioeconomic status, environmental air pollution, exposure to tobacco smoke, birth during pollen season, no older 
siblings, exposure to allergens such as animal dander and dust mites $[2,3,11,12]$. The findings are inconsistent and the major determinant contributing to the development of allergic rhinitis is still unclear. Few air pollution studies have addressed allergic rhinitis as an endpoint with some suggesting that exposure to air pollutants may increase its risk [13]. Studies have also reported that living in closed proximity to a major road with high volumes of motor vehicles or truck traffic is associated symptoms of allergic diseases, due to high levels of air pollutants from traffic [14]. The majority of epidemiological studies emanate from developed countries; little is known about such association in developing countries. In South Africa, AR is an important and common condition encountered in most communities and affecting anywhere from 20 to $30 \%$ of the population. However, data from South Africa is limited, with infrequent updates on circulating aeroallergens and the possible impact of climate change [15].

Existing studies are not generalised; some have small sample sizes and assess specific populations [16, 17]. One study that was carried out in Cape Town, Western Cape Province, reported an increase in the symptoms over a 7 year period, from $30.4 \%$ in 1995 to $38.5 \%$ in 2003 [18]. The main aim of this study was to investigate the association between traffic related-air pollution and allergic rhinitis, current rhinoconjunctivitis and hayfever symptoms amongst children attending schools in Tembisa and Kempton Park areas of Ekurhuleni Metropolitan Municipality (EMM), Gauteng Province, South Africa.

\section{Methods}

\section{Study area}

The study was conducted in Tembisa and Kempton Park areas, which fall under the EMM. Tembisa is the second largest township in Gauteng Province, with both formal and informal housing, being home mainly to people belonging to Black/African ethnic groups. The main air polluting sources in the area includes, amongst others, residential fuel burning (particularly coal), industrial and commercial fuel burning (coal-fired boilers in close proximity to residential areas) and vehicular exhaust emissions (both petrol and diesel) [19]. Kempton Park is a suburban area surrounded by industry and arterial roads connecting Gauteng Province. The OR Tambo International Airport, which is Africa's busiest airport, is also located nearby. Vehicular exhaust emissions (both petrol and diesel), industrial and commercial fuel burning (coalfired boilers in close proximity to residential areas), OR Tambo International Airport (contributing a small fraction of low level, concentrated $\mathrm{NO}_{2}$ ) and large industries associated with various stack, vent and fugitive emissions were identified as significantly contributing to air pollution [19]. The (EMM) where the two areas are located falls under the Highveld Region, which was declared an air pollution priority area in the country, due to poor air quality, which is still the worst to date [20].

\section{Study design, population and sample selection}

A cross-sectional epidemiological study was conducted between February and June 2012, following the International Study of Asthma and Allergies in Childhood (ISAAC) Phase I protocol [21]. The ISAAC was designed as a multicentre-study to investigate the epidemiology of asthma, rhinitis and atopic dermatitis amongst children using standardised definitions, allowing comparisons worldwide [21]. A list of all schools (primary and secondary) in EMM was provided by the Gauteng Department of Education. All primary schools were excluded and 16 high schools were randomly selected from the list of high schools. Each school was contacted and requested to participate in the study. Following approval by the principal and governing body in each school, all eligible children between the ages of 13 and 14 years and in Grade 8 were requested to participate. The 13 to 14 year age group was chosen because it is the age most adolescents go to school regularly, making data collection easier. Each school was requested to make available a copy of class lists. An appointment was scheduled with the school to deliver the consent forms for the children two weeks prior to the study and they were requested to return them within three days. The study population consisted of 3764 , children based on the numbers given by each school prior to data collection. Data were collected using the English version of ISAAC written questionnaires. The questionnaires were completed by the children in the classroom under the supervision of the data collectors, who were specifically trained and briefed to avoid explanations which could interfere with the participant's answers.

\section{Health outcomes}

In this study we estimated health outcomes on the basis of positive answers from the written ISAAC questionnaire for 13 to 14 years old. Answers to written questions were self-reported by children. Questions on symptoms relating to rhinitis were as follows:

1. Rhinitis ever: Have you ever had a problem with sneezing or runny or blocked nose, when you DID NOT have a cold or flu? (Yes/No)

2. Current rhinitis: In the past 12 months, have you had a problem with sneezing or a runny or blocked 
nose, when you DID NOT have a cold or the flu? (Yes/No)

3. Current rhinoconjunctivitis: In the past 12 months, has this nose problem been accompanied by itchywatery eyes? (Yes/No)

4. In which of the past 12 months, has this nose problem been accompanied by itchy-watery eyes? (Month names listed).

5. In the past 12 months, how much did this nose problem interfere with your daily activities? (Not at all, a little, a moderate amount, a lot)

6. Hayfever: Have you ever had hayfever? (Yes/No)

\section{The main independent variables}

Information regarding exposure to traffic-related pollution was obtained through the following questions: how often do tucks pass near your home on weekdays? (Never, seldom, frequently through the day, almost all day).

\section{Confounders}

A priori selection of the following confounding was done: sex (male/female), being born in Tembisa/Kempton Park the area (yes/no), type of house (brick, mud, corrugated iron, combination), vigorous physical activity (never/occasionally/1-2 times per week/, $\geq 3$ times per week); How do you usually get to school? walk, taxi/bus, motorcar, combination of motorcar/taxi or train; hours watching television per day $(<1 \mathrm{~h} / 1 \mathrm{~h}$ but $<3 \mathrm{~h} / 3 \mathrm{~h}$ but $<5 \mathrm{~h} / \geq 5 \mathrm{~h}$ ) in $24 \mathrm{~h}$; ETS exposure at home in the past 30 days (yes/no), ETS exposure at school in the past 30 days (yes/no), tobacco smoking by participant (yes/no), mother/father smoking tobacco (yes/no), any other person smoking at home other than participant (yes/no). Children were asked to select the most frequently used energy source at home; they had to select one type of energy source: for cooking at home (electricity, gas, paraffin, open fires) and for heating (electricity, gas, paraffin, open fires). Other variables, which were included in the questionnaire but not selected as confounders and were only reported in the descriptive analysis, were: period lived in the residential area ( $<6$ months/ 6 to 12 months/ 1 to 2 years/ $\geq 3$ years), the variables.

\section{Data management and statistical analysis}

The data were entered into a database set up in EpiInfo V3.5.3. Stata Version 12 was applied for the data analysis. Prevalence rates for the health outcomes and proportion on risk factors under investigation were calculated by dividing the number of participants who responded affirmatively to a particular question by the number of questionnaires completed. Observations marked as "do not know", "not stated" or "other responses" were set as missing. This resulted in each question having a slightly different sample size. Crude and adjusted odds ratios (OR) and
$95 \%$ confidence intervals $(\mathrm{CI})$ were calculated with multilevel logistic regression analysis (MLRA) with random effect to estimate the likelihood of having rhinitis ever, current rhinitis, rhinoconjunctivitis and hayfever health outcomes given the presence of a potential risk factor. The multilevel data included sixteen schools nested within two districts (level 1). Confounding variables were added in a stepwise manner, starting with the most significant from the univariate analysis. Each time a new potential confounder was added to the model, if the effect estimate between the exposure of interest and respiratory outcome already in the models changed by more than $5 \%$, the additional variable was retained in the final multiple MLRA, otherwise the variable was removed and a different one was added [22]. This resulted in the final models having slightly different confounders. The most parsimonious multiple MLRA models were reported, i.e., those with variables having a p-value $<0.05$ [22].

\section{Ethical considerations}

The Ethics and Research Committee of the Faculty of Health Sciences, University of Pretoria approved the study (Ethics Number: S121/2011). The Gauteng Department of Education, Ekurhuleni North District, school principals and governing bodies were approached and gave approval and cooperation for the study. Parents of participants were sent a letter explaining the details and nature of the study and gave consent for the children to participate in the study. All information was kept confidential.

\section{Results}

The study population consisted of 3764 children from 16 schools. A total of 3468 completed the questionnaires (92\% response rate). The study focused on children who were present at school during at the time of fieldwork and so 296 learners did not participate. The teachers gave assurance that most of the children were present. School attendance was high during the study therefore bias that may have been introduced by non-response rate was assumed to be relatively low. Forty-four questionnaires were excluded during the data capturing due to incomplete information. A total of 3424 questionnaires were finally included in the data analysis.

The frequencies and percentages for health outcomes and general characteristics of children are summarised in Table 1. The prevalence of rhinitis ever was $52.3 \%$, current rhinitis $40.1 \%$ rhinoconjunctivitis $22.5 \%$ and hayfever $37 \%$. Girls accounted for $52 \%$ of the participants. The majority of the children lived in Tembisa Township (67.2 \%) and more than three quarters had lived in the same area for more than 3 years (76.2 \%). Fifty three percent of the children were born within the study areas. The majority of the children lived in formal housing structures $(86.11 \%)$. Forty one percent of the 
Table 1 Health outcomes and demographic characteristics of the study participants $(n=3424)$

\begin{tabular}{llc}
\hline Variable & Total & Percentage \\
\hline Rhinitis ever & 1790 & 52.3 \\
Current rhinitis & 1372 & 40.1 \\
Current rhinoconjunctivitis & 769 & 22.5 \\
Ever had hayfever & 1285 & 37.5
\end{tabular}

Sex of child

Female

1790

Male

1634

Type of Area

Township

2301

Suburb

1117

Missing

6

Period lived in the area

Less than 6 months

6 to 12 months

1 to 2 years

3 years and longer

2609

Born in the areas of Tembisa and Kempton Park

Yes

No

1609

Missing

3

Type of house

Brick

2938

Mud

Corrugated iron

Combination

184

Missing

126

Vigorous physical activity per week

Never or occasionally

Once or twice per week

1417

Three or more times a week

983

Missing

40

Hours watching television on average in a day

$$
\text { Less than } 1 \mathrm{~h}
$$

532

Hour but less than $3 \mathrm{~h}$

835

$2 \mathrm{~h}$ but less than $5 \mathrm{~h}$

$$
827
$$

More than $5 \mathrm{~h}$

1213

Missing

17

ETS exposure at home in the past 30 days

$$
\text { Yes }
$$

No

1460

Missing

41.4

28.7

1.2

\begin{tabular}{|c|c|c|}
\hline \multicolumn{3}{|c|}{ ETS exposure at school in the past 30 days } \\
\hline Yes & 1177 & 34.4 \\
\hline No & 1452 & 42.4 \\
\hline Missing & 755 & 23.2 \\
\hline \multicolumn{3}{|c|}{ Residential cooking fuel type most frequently used } \\
\hline Electricity & 2995 & 87.5 \\
\hline Gas & 179 & 5.2 \\
\hline Paraffin & 200 & 5.8 \\
\hline Open fires (wood, coal) & 30 & 0.9 \\
\hline Missing & 20 & 0.6 \\
\hline \multicolumn{3}{|c|}{ Residential heating fuel type most frequently used } \\
\hline Electricity & 2041 & 59.6 \\
\hline Gas & 426 & 12.4 \\
\hline Paraffin & 631 & 18.4 \\
\hline Open fires (wood, coal) & 270 & 7.9 \\
\hline Missing & 56 & 1.64 \\
\hline \multicolumn{3}{|l|}{ Mode of transport to school } \\
\hline Walk & 1728 & 50.5 \\
\hline Taxi\Bus & 708 & 20.7 \\
\hline Motor car & 683 & 20.0 \\
\hline Combination & 201 & 5.9 \\
\hline Train & 100 & 2.9 \\
\hline Missing & 4 & 0.1 \\
\hline \multicolumn{3}{|c|}{ Frequency of trucks passing near homes on weekdays } \\
\hline Never & 563 & 16.4 \\
\hline Seldom & 1033 & 30.2 \\
\hline Frequently through the day & 580 & 16.9 \\
\hline Almost every day & 1212 & 35.4 \\
\hline Missing & 36 & 1.1 \\
\hline
\end{tabular}

Table 1 Health outcomes and demographic characteristics of the study participants $(n=3424)$ (Continued) children engaged in vigorous physical activity once or twice per week, $29 \%$ three or more times per week, the other $30 \%$ never or occasionally. Forty two percent were exposed to tobacco smoke at home, whilst $34 \%$ were exposed at school. A small percentage of pupils reported the use of gas (5.2 \%) and paraffin (5.8 \%) for cooking at home, while the majority used electricity $(87.5 \%)$. Trucks passing near residences almost all day were reported by $35.4 \%$ of the children. Just over half of the children walked to school (50.5\%), while the other half used other modes of transport (cars, taxi, buses and train).

Table 2, summarise the MLRA results for the frequency of truck traffic and symptoms of rhinitis ever, current rhinitis, current rhinoconjunctivitis and 
Table 2 Frequency of truck traffic and symptoms of rhinitis ever, current rhinitis, current rhinoconjunctivitis and hayfever along with crude and adjusted odd ratios

\begin{tabular}{|c|c|c|c|c|c|c|}
\hline Frequency of trucks passing near homes on weekdays & Total $^{e}$ & $(\%)$ & Crude OR $(95 \% \mathrm{Cl})$ & $P$ & Adjusted OR (95\% Cl) & $P$ \\
\hline \multicolumn{7}{|l|}{ Rhinitis ever ${ }^{a}$} \\
\hline Never & 563 & 47.3 & 1 & & 1 & \\
\hline Seldom & 1033 & 53.1 & $1.26(1.02-1.55)$ & 0.027 & $1.16(0.92-1.56)$ & 0.197 \\
\hline Frequently through the day & 580 & 49.3 & $1.09(0.86-1.37)$ & 0.451 & $1.03(0.79-1.34)$ & 0.791 \\
\hline Almost all day & 1212 & 55.9 & $1.43(1.16-1.75)$ & 0.001 & $1.46(1.16-1.84)$ & 0.001 \\
\hline \multicolumn{7}{|l|}{ Current rhinitis $^{\mathrm{b}}$} \\
\hline Never & 563 & 34.6 & 1 & & 1 & \\
\hline Seldom & 1033 & 41.2 & $1.25(1.01-1.55)$ & 0.038 & $1.30(0.99-1.62)$ & 0.059 \\
\hline Frequently through the day & 580 & 39.1 & $1.23(0.97-1.57)$ & 0.081 & $1.25(0.95-1.64)$ & 0.102 \\
\hline Almost all day & 1212 & 42.5 & $1.46(1.88-1.81)$ & 0.000 & $1.60(1.24-2.02)$ & 0.000 \\
\hline \multicolumn{7}{|l|}{ Current rhinoconjunctivitis $^{c}$} \\
\hline Never & 563 & 18.8 & 1 & & 1 & \\
\hline Seldom & 1033 & 23.0 & $1.23(0.95-1.59)$ & 0.113 & $1.17(0.89-1.54)$ & 0.234 \\
\hline Frequently through the day & 580 & 19.0 & $1.01(0.75-1.37)$ & 0.904 & $0.96(0.70-1.30)$ & 0.799 \\
\hline Almost all day & 1212 & 25.7 & $1.54(1.20-1.97)$ & 0.001 & $1.42(1.09-1.84)$ & 0.008 \\
\hline \multicolumn{7}{|l|}{ Hayfever $^{d}$} \\
\hline Never & 563 & 32.7 & 1 & & 1 & \\
\hline Seldom & 1033 & 38.7 & $1.22(0.98-1.51)$ & 0.074 & $1.12(0.87-1.43)$ & 0.362 \\
\hline Frequently through the day & 580 & 37.9 & $1.28(1.00-1.63)$ & 0.047 & $1.19(0.90-1.57)$ & 0.203 \\
\hline Almost all day & 1212 & 38.2 & $1.34(1.08-1.66)$ & 0.007 & $1.23(0.96-1.57)$ & 0.087 \\
\hline
\end{tabular}

a, bodel adjusted for the folowing $v$ mode of transport to school, being born in the area, vigorous physical activity, ETS exposure at home in the past 30 days, residential fuel heating type most frequently used at home

${ }^{c}$ Model adjusted for mode of transport to school, being born in the area, vigorous physical activity, hours watching TV during normal week, residential heating fuel type most frequently used at home

${ }^{\mathrm{d}}$ Model adjusted for vigorous physical activity, residential fuel heating type most frequently used at home, ETS exposure at home

${ }^{\mathrm{e}}$ Totals for each risk factor are different due to difference in missing values

hayfever along with crude and adjusted odd ratios (for further results see Appendix). Rhinitis ever; current rhinitis and current rhinoconjunctivitis were significantly associated with the frequency of trucks passing near residences almost all day on weekdays, (OR 1.4695 \% CI: $1.16-1.84$ ), (OR 1.6095 \% CI: 1.24-2.02) and (OR 1.4295 \% CI: 1.09-1.84) respectively. No association was observed between truck traffic and hayfever in the multiple analyses.

The following confounding variables were associated with the health outcomes: the likelihood of rhinitis ever, current rhinitis, current rhinoconjunctivitis and hayfever were less for males, (OR 1.2295 \% CI: 1.051.43), (OR $0.8295 \%$ CI: 0.70-0.96), (OR $0.6895 \%$ CI: $0.57-0.81$ ) and (OR $0.5695 \%$ CI: $0.47-0.65$ ). Rhinitis ever was associated with vigorous physical activity once or twice per week OR $1.2795 \%$ CI: 1.061.53), ETS exposure at home (OR $1.1595 \%$ CI: 0.99-1.34). Current rhinitis was associated with being born in the area OR $0.8295 \%$ CI: 0.70-0.96), vigorous physical activity once or twice per week OR 1.27
$95 \%$ CI: 1.05-1.53), the use of gas for heating OR $1.3195 \%$ CI: (1.04-1.65) and ETS at home (OR 1.16 95 \% CI: 0.99-1.36). Rhinoconjunctivitis was associated with being born in the area (OR $1.2295 \%$ CI:(1.02-1.45), vigorous physical activity once or twice per week (OR $1.4295 \%$ CI: 1.16-1.76) and three or more times a week (OR $1.3495 \%$ CI: 1.06-1.68), watching TV per week day (OR $1.3795 \%$ CI: 1.061.78) and gas frequently used for heating at home (OR 1.4595 \% CI: 1.14-1.85). Hay fever, sex, vigorous physical activity once or twice per week (OR 1.38 $95 \% \mathrm{CI}: 1.44-1.68)$ and three or more times per week (OR $1.5295 \%$ CI: 1.23-1.88), open fires used for heating (OR $1.5195 \%$ CI 1.13-2.02) and exposure to tobacco smoke at home (OR 1.2095 \% CI: 1.02-1.40). Rhinitis ever and current rhinitis were associated with using a combination of walking and taxi/bus as mode of transport to school; (OR 1.45 95 \% CI: 1.04-2.04), (OR 1.8195 \% CI: 1.21-2.71). No association was observed between hayfever and rhinoconjunctivitis with mode of transport to school. 


\section{Discussion}

The study investigated the association between the frequency of truck traffic and allergic rhinitis symptoms, rhinoconjunctivitis and hayfever amongst 13 to 14 year old school children attending schools in areas of Tembisa and Kempton Park, located in EMM. The prevalence of rhinitis ever was $52.3 \%$, current rhinitis $40.1 \%$, rhinoconjunctivitis $22.5 \%$ and hayfever $37 \%$. The prevalence of childhood allergic rhinitis shows wide variation throughout the world, ranging from 0.8 to $39.7 \%$ [23]. The prevalence of rhinitis ever reported for this study is close to that reported for Turkish adolescents of $53.5 \%$, while current rhinitis was slightly higher at (38.3\%) [24], and similar to that in Bogotá, Colombia, which was $36.7 \%$ [10]. The prevalence of current rhinitis in this study was high, in contrast to that (14.9\%) reported in Budapest [25] and to that reported in two previous studies conducted in Cape Town, South Africa, $30 \%$ in 1999 and $38 \% 2003$ [18]. Twenty-two centres across the African continent participated in Phase III of the ISAAC study. There were considerable variations in the prevalence of allergic rhinoconjunctivitis within the participating centres (7.2-27.3\%). A number of centres showed high symptoms of allergic rhinoconjunctivitis (Cape Town, Reunion Island, Brazzaville, Eldoret, Urban Ivory Coast, Conakry, Casablanca, Wilays of Algiers and Sousse) [23].

Trucks passing near homes almost the whole day during weekdays increased the likelihood of rhinitis ever, current rhinitis and current rhinoconjunctivitis. Studies have previously reported on the association between traffic-related pollution and allergic rhinitis symptoms. A study conducted in Bochum, Germany reported a positive relationship between the prevalence of wheezing and allergic rhinitis and the indicators of traffic density [26]. A positive global relationship between childhood symptoms of rhinoconjunctivitis and self-reported truck traffic on the street of residence were reported from studies that were conducted in 110 ISAAC centres globally [27]. A crosssectional study conducted amongst 32,143 Taiwanese school children found that allergic rhinitis was associated with urban levels of $\mathrm{SO}_{2}$, carbon monoxide (CO) and $\mathrm{NO}_{\mathrm{X}}$ (traffic-related air pollution $\mathrm{NOx}$ and CO) [28]. A present report by the World Health Organization found evidence linking health effects to traffic-related pollution [29]. In recent years, South Africa, particularly Gauteng Province, has experienced an increase in the number of cars and trucks on the road. The total number of live vehicles (licenced) in Gauteng province, where the EMM is located was over 4.4 million, in April 2015 [30]. Vehicles, particularly trucks, are known to release polluting chemicals into the atmosphere, which may have respiratory effects on nearby residents. It is plausible that the observed association between health outcomes is linked to the increased level of pollution in the area.
Certain limitations should be taken into account in the interpretation of the results. Firstly, the study had a cross-sectional epidemiological design. The results of the study might be higher than the actual prevalence since the results are based on self-reported answers from the questionnaire. With cross-sectional studies, where a questionnaire is administered to collect data and participants are questioned on the presence of nasal symptoms, a significantly higher rate of symptoms is reported than for true allergic rhinitis [16]. However, cross-sectional studies are important indicators of health problems occurring in communities and serve as a baseline for further analytical and experimental investigation.

Secondly, we adjusted for confounding variable such as sex, being born in the area, physical activity, hours watching TV daily, mode of transport tot school; however there many other risk factors such as genetics, environmental factors and allergens which may play a role in the development and exacerbation of rhinitis. Thirdly, information on traffic density as an indicator of exposure to traffic related pollution was also taken from selfreports from children. The frequency of trucks passing near homes on weekdays may have been misclassified, as on weekdays children are at school. Furthermore, the traffic density may not accurately reflect the exposure the children experience inside and outside their homes. Children who are aware of the possible health effects of traffic-related air pollution and who have had symptoms may report exposure. Future studies should attempt to compare questionnaire responses with traffic data.

Fourthly, no quantitative air pollution exposures assessments were conducted during the study; we were not able to validate the participant's responses by checking individual addresses or by measuring ambient pollution levels in or near their homes, as we did not have addresses. However, the findings are consistent with results of other studies, suggesting that traffic-related air pollution exacerbates existing conditions or increases the likelihood of the development of allergic rhinitis. Fifthly, although the study was done in an air pollution priority area, on the basis of multiple sources of air pollution; only proximity to truck traffic was investigated as an ambient (outdoor source) exposure variable. We did not include any other questions e.g., on distance of industries from residential areas. More research should be conducted in the area to investigate other outdoor air pollution sources. Studies should be conducted amongst children in the area to test for allergen triggering or exacerbating rhinitis symptoms.

Lastly the study was conducted from February to June 2012, in South Africa February to April falls is autumn, while May to July fall within winter, it is possible where data was collected in winter months children may have reported more symptoms than those surveyed during autumn months. Despite the limitations, there are also 
strengths which should be noted. The ISAAC questionnaire has been shown to be valid for this age group and has been used extensively in international studies relating to symptoms of rhinitis. Secondly, a larger sample size of more than 3000 children, as required by ISAAC centres, would increase the statistical power for the study.

\section{Conclusion}

The study found an association between the frequency of trucks near residences and symptoms of rhinitis, rhinoconjunctivitis and hayfever 13 to 14 years old children, attending schools in Tembisa and Kempton Park located in EMM. This study will serve as a suitable baseline for monitoring future trends in the prevalence of allergic rhinitis amongst children in this particular area, which is known to have poor air quality.

\section{Appendix}

Table 3 The prevalence of self-reported rhinitis ever along with crude and adjusted odd ratios

\begin{tabular}{|c|c|c|c|c|c|c|}
\hline Variable & Total $^{a}$ & Rhinitis ever ${ }^{\mathrm{a}}(\%)$ & Crude OR $(95 \% \mathrm{Cl})$ & $P$ & Adjusted OR $(95 \% \mathrm{Cl})^{\mathrm{b}}$ & $P$ \\
\hline \multicolumn{7}{|l|}{ Mode of transport to school } \\
\hline Walk & 1728 & 51.7 & 1 & & 1 & \\
\hline Taxi/Bus & 708 & 49.7 & $0.92(0.77-1.10)$ & 0.400 & $0.99(0.81-1.21)$ & 0.965 \\
\hline Motor car & 683 & 53.9 & $1.08(0.90-1.29)$ & 0.358 & $1.15(0.93-1.42)$ & 0.186 \\
\hline Combination & 201 & 60.8 & $1.42(1.05-1.92)$ & 0.019 & $1.45(1.04-2.04)$ & 0.028 \\
\hline Train & 100 & 53.0 & $1.05(0.70-1.58)$ & 0.798 & $1.13(0.71-1.81)$ & 0.582 \\
\hline \multicolumn{7}{|c|}{ Frequency of trucks passing near homes on weekdays } \\
\hline Never & 563 & 47.3 & 1 & & 1 & \\
\hline Seldom & 1033 & 53.1 & $1.26(1.02-1.55)$ & 0.027 & $1.16(0.92-1.56)$ & 0.197 \\
\hline Frequently through the day & 580 & 49.3 & $1.09(0.86-1.37)$ & 0.451 & $1.03(0.79-1.34)$ & 0.791 \\
\hline Almost all day & 1212 & 55.9 & $1.43(1.16-1.75)$ & 0.001 & $1.46(1.16-1.84)$ & 0.001 \\
\hline \multicolumn{7}{|c|}{ Being born in Tembisa/Kempton park areas } \\
\hline No & 1609 & 49.3 & 1 & & 1 & \\
\hline Yes & 1812 & 54.9 & $1.28(1.11-1.47)$ & 0.000 & $1.22(1.05-1.43)$ & 0.008 \\
\hline \multicolumn{7}{|l|}{ Vigorous physical activity } \\
\hline Never or occasionally & 984 & 49.1 & 1 & & 1 & \\
\hline Once or twice per week & 1417 & 54.8 & $1.26(1.07-1.48)$ & 0.005 & $1.27(1.06-1.53)$ & 0.008 \\
\hline 3 or more times per week & 983 & 52.1 & $1.12(0.94-1.34)$ & 0.193 & $1.08(0.88-1.31)$ & 0.447 \\
\hline \multicolumn{7}{|c|}{ ETS exposure at home in the past 30 days } \\
\hline No & 1460 & 51.3 & 1 & & 1 & \\
\hline Yes & 1452 & 55.7 & $1.19(1.03-1.38)$ & 0.017 & $1.15(0.99-1.34)$ & 0.056 \\
\hline \multicolumn{7}{|c|}{ Residential heating fuel type most frequently used } \\
\hline Electricity & 2041 & 51.4 & 1 & & 1 & \\
\hline Gas & 426 & 56.3 & $1.23(0.99-1.52)$ & 0.055 & $1.23(0.98-1.56)$ & 0.070 \\
\hline Paraffin & 631 & 52.9 & $1.07(0.87-1.31)$ & 0.487 & $1.04(0.84-1.28)$ & 0.694 \\
\hline Open fire & 270 & 51.1 & $0.99(0.76-1.28)$ & 0.973 & $1.07(0.80-1.14)$ & 0.621 \\
\hline
\end{tabular}

${ }^{\mathrm{a}}$ Totals for each risk factor are different due to difference in missing values

${ }^{\mathrm{b}}$ Model adjusted for all the variables in this table 
Table 4 The prevalence of self-reported current rhinitis with crude and adjusted odd ratios

\begin{tabular}{|c|c|c|c|c|c|c|}
\hline Variable & Total $^{a}$ & Current rhinitis (\%) & Crude OR $(95 \% \mathrm{Cl})$ & $P$ & Adjusted OR $(95 \% \mathrm{Cl})^{\mathrm{b}}$ & $P$ \\
\hline \multicolumn{7}{|l|}{ Mode of transport to school } \\
\hline Walk & 1728 & 37.1 & 1 & & 1 & \\
\hline Taxi/Bus & 708 & 40.1 & $1.11(0.92-1.33)$ & 0.253 & $1.15(0.93-1.42)$ & 0.194 \\
\hline Motor car & 683 & 43.2 & $1.18(0.92-1.51)$ & 0.169 & $1.31(0.92-1.87)$ & 0.127 \\
\hline Combination & 201 & 52.7 & $1.75(1.27-2.43)$ & 0.001 & $1.81(1.21-2.71)$ & 0.004 \\
\hline Train & 100 & 44.0 & $1.27(0.83-1.93)$ & 0.259 & $1.40(0.86-2.27)$ & 0.172 \\
\hline \multicolumn{7}{|c|}{ Frequency of trucks passing near homes on weekdays } \\
\hline Never & 563 & 34.6 & 1 & & 1 & \\
\hline Seldom & 1033 & 41.2 & $1.25(1.01-1.55)$ & 0.038 & $1.30(0.99-1.62)$ & 0.059 \\
\hline Frequently through the day & 580 & 39.1 & $1.23(0.97-1.57)$ & 0.081 & $1.25(0.95-1.64)$ & 0.102 \\
\hline Almost all day & 1212 & 42.5 & $1.46(1.88-1.81)$ & 0.000 & $1.60(1.24-2.02)$ & 0.000 \\
\hline \multicolumn{7}{|l|}{ Sex } \\
\hline Female & 1790 & 43.0 & 1 & & 1 & \\
\hline Male & 1634 & 37.0 & $0.77(0.67-0.89)$ & 0.000 & $0.82(0.70-0.96)$ & 0.016 \\
\hline \multicolumn{7}{|l|}{ Born within the area } \\
\hline No & 1609 & 37.6 & & & 1 & \\
\hline Yes & 1812 & 42.2 & $1.29(1.12-1.49)$ & 0.000 & $0.82(0.70-0.96)$ & 0.013 \\
\hline \multicolumn{7}{|l|}{ Vigorous physical activity } \\
\hline Never or occasionally & 984 & 37.2 & 1 & & 1 & \\
\hline Once or twice per week & 1417 & 42.2 & $1.22(1.03-1.44)$ & 0.017 & $1.27(1.05-1.53)$ & 0.012 \\
\hline 3 or more times per week & 983 & 40.2 & $1.10(0.92-1.33)$ & 0.263 & $1.08(0.88-1.34)$ & 0.424 \\
\hline \multicolumn{7}{|c|}{ Residential heating fuel type most frequently used } \\
\hline Electricity & 2041 & 40.3 & 1 & & 1 & \\
\hline Gas & 426 & 46.0 & $1.26(1.02-1.56)$ & 0.029 & $1.31(1.04-1.65)$ & 0.022 \\
\hline Paraffin & 631 & 36.3 & $0.93(0.76-1.13)$ & 0.466 & $0.88(0.70-1.11)$ & 0.289 \\
\hline Open fire & 270 & 39.2 & $1.01(0.77-1.31)$ & 0.934 & $1.09(0.81-1.46)$ & 0.553 \\
\hline \multicolumn{7}{|l|}{ Exposure to ETS at home } \\
\hline No & 1460 & 39.0 & 1 & & 1 & \\
\hline Yes & 1452 & 42.0 & $1.16(1.00-1.34)$ & 0.048 & $1.16(0.99-1.36)$ & 0.054 \\
\hline
\end{tabular}

Totals for each risk factor are different due to difference in missing values

${ }^{\mathrm{b}}$ Model adjusted for all the variables in this table 
Table 5 Prevalence of self-reported current rhinoconjunctivitis along with crude and adjusted odd ratios

\begin{tabular}{|c|c|c|c|c|c|c|}
\hline Variable & Total $^{a}$ & Allergic rhino-conjunctivitis (\%) & Crude OR $(95 \% \mathrm{Cl})$ & $P$ & Adjusted OR $(95 \% \mathrm{Cl})^{\mathrm{b}}$ & $P$ \\
\hline \multicolumn{7}{|l|}{ Mode of transport to school } \\
\hline Walk & 1728 & 20.7 & 1 & & 1 & \\
\hline Taxi/Bus & 708 & 22.3 & $1.09(0.88-1.35)$ & 0.387 & $1.06(0.84-1.33)$ & 0.615 \\
\hline Motor car & 683 & 24.6 & $1.25(1.01-1.54)$ & 0.033 & $1.19(0.87-1.62)$ & 0.260 \\
\hline Combination & 201 & 26.4 & $1.53(1.10-2.12)$ & 0.011 & $1.44(0.98-2.11)$ & 0.054 \\
\hline Other & 100 & 27.0 & $1.46(0.92-2.30)$ & 0.105 & $1.57(0.96-2.57)$ & 0.068 \\
\hline \multicolumn{7}{|c|}{ Frequency of trucks passing near homes on weekdays } \\
\hline Never & 563 & 18.8 & 1 & & 1 & \\
\hline Seldom & 1033 & 23.0 & $1.23(0.95-1.59)$ & 0.113 & $1.17(0.89-1.54)$ & 0.234 \\
\hline Frequently through the day & 580 & 19.0 & $1.01(0.75-1.37)$ & 0.904 & $0.96(0.70-1.30)$ & 0.799 \\
\hline Almost all day & 1212 & 25.7 & $1.54(1.20-1.97)$ & 0.001 & $1.42(1.09-1.84)$ & 0.008 \\
\hline \multicolumn{7}{|l|}{ Sex } \\
\hline Female & 1790 & 25.8 & 1 & & 1 & \\
\hline Male & 1634 & 18.9 & $0.67(0.57-0.79)$ & 0.000 & $0.68(0.57-0.81)$ & 0.000 \\
\hline \multicolumn{7}{|c|}{ Being born in Tembisa/Kempton park areas } \\
\hline No & 1609 & 20.7 & 1 & & 1 & \\
\hline Yes & 1812 & 24.0 & $1.27(1.07-1.50)$ & 0.004 & $1.22(1.02-1.45)$ & 0.024 \\
\hline \multicolumn{7}{|l|}{ Vigorous physical activity } \\
\hline Never or occasionally & 984 & 18.4 & 1 & & 1 & \\
\hline Once or twice per week & 1417 & 24.8 & $1.45(1.19-1.78)$ & 0.000 & $1.42(1.16-1.76)$ & 0.001 \\
\hline 3 or more times per week & 983 & 23.3 & $1.33(1.06-1.65)$ & 0.011 & $1.34(1.06-1.68)$ & 0.012 \\
\hline \multicolumn{7}{|c|}{ Hours watching TV during normal week } \\
\hline Less than $1 \mathrm{~h}$ & 532 & 19.6 & & & 1 & \\
\hline $1 \mathrm{~h}$ but less than $3 \mathrm{~h}$ & 835 & 19.8 & $0.97(0.74-1.28)$ & 0.873 & $0.93(0.69-1.24)$ & 0.622 \\
\hline $3 \mathrm{~h}$ but less than $5 \mathrm{~h}$ & 827 & 23.1 & $1.20(0.91-1.57)$ & 0.180 & $1.15(0.87-1.53)$ & 0.313 \\
\hline $5 \mathrm{~h}$ or more & 1213 & 25.1 & $1.37(1.07-1.77)$ & 0.012 & $1.37(1.06-1.78)$ & 0.016 \\
\hline \multicolumn{7}{|c|}{ Residential heating fuel type most frequently used } \\
\hline Electricity & 2041 & 21.5 & 1 & & 1 & \\
\hline Gas & 426 & 29.3 & $1.50(1.18-1.89)$ & 0.001 & $1.45(1.14-1.85)$ & 0.002 \\
\hline Paraffin & 631 & 20.1 & $0.96(0.76-1.22)$ & 0.760 & $0.95(0.75-1.22)$ & 0.739 \\
\hline Open fires (wood, coal) & 270 & 24.1 & $1.18(0.87-1.59$ & 0.276 & $1.18(0.86-1.61)$ & 0.291 \\
\hline
\end{tabular}


Table 6 Prevalence of self-reported hayfever along with crude and adjusted odd ratios, by risk or protective factors

\begin{tabular}{|c|c|c|c|c|c|c|}
\hline Variable & Total $^{\mathrm{a}}$ & Hayfever (\%) & Crude OR (95 \% Cl) & $\mathrm{p}$ & Adjusted OR $(95 \% \mathrm{Cl})^{\mathrm{b}}$ & $\mathrm{p}$ \\
\hline \multicolumn{7}{|c|}{ Frequency of trucks passing near homes on weekdays } \\
\hline Never & 563 & 32.7 & 1 & & 1 & \\
\hline Seldom & 1033 & 38.7 & $1.22(0.98-1.51)$ & 0.074 & $1.12(0.87-1.43)$ & 0.362 \\
\hline Frequently through the day & 580 & 37.9 & $1.28(1.00-1.63)$ & 0.047 & $1.19(0.90-1.57)$ & 0.203 \\
\hline Almost all day & 1212 & 38.2 & $1.34(1.08-1.66)$ & 0.007 & $1.23(0.96-1.57)$ & 0.087 \\
\hline \multicolumn{7}{|l|}{ Sex of child } \\
\hline Female & 1790 & 43.2 & 1 & & 1 & \\
\hline Male & 1634 & 31.3 & $0.59(0.51-0.68)$ & 0.000 & $0.56(0.47-0.65)$ & 0.000 \\
\hline \multicolumn{7}{|l|}{ Vigorous physical activity per week } \\
\hline Never or occasionally & 984 & 30.7 & 1 & & 1 & \\
\hline Once or twice per week & 1417 & 40.2 & $1.51(1.27-1.80)$ & 0.000 & $1.38(1.44-1.68)$ & 0.001 \\
\hline Three or more times per week & 983 & 40.5 & $1.48(1.23-1.79)$ & 0.000 & $1.52(1.23-1.88)$ & 0.000 \\
\hline \multicolumn{7}{|c|}{ Residential fuel heating type most frequently } \\
\hline Electricity & 2041 & 35.8 & 1 & & & \\
\hline Gas & 426 & 43.0 & $1.30(1.05-1.61)$ & 0.015 & $1.20(0.95-1.52)$ & 0.121 \\
\hline Paraffin & 631 & 35.8 & $1.15(0.94-1.40)$ & 0.160 & $1.11(0.89-1.39)$ & 0.330 \\
\hline Open fire & 270 & 43.3 & $1.46(1.12-1.89)$ & 0.004 & $1.51(1.13-2.02)$ & 0.005 \\
\hline \multicolumn{7}{|l|}{ ETS exposure at home } \\
\hline No & 1460 & 36.1 & 1 & & 1 & \\
\hline Yes & 1452 & 40.1 & $1.23(1.05-1.43)$ & 0.007 & $1.20(1.02-1.40)$ & 0.022 \\
\hline
\end{tabular}

${ }^{a}$ Totals for each risk factor are different due to difference in missing values

${ }^{\mathrm{b}}$ Model adjusted for all the variables in this table

\section{Abbreviations}

BC: Black carbon; Cl: Confidence intervals; EMM: Ekurhuleni metropolitan municipality; ETS: Environmental tobacco smoke; OR: Odds ratio; ISAAC: International study of asthma and allergies in childhood; LRA: Logistic regression analysis; UFP: Ultra-fine particles.

\section{Competing interest}

The authors declare they have no competing interests.

\section{Authors' contributions}

JS participated in the design of the study, acquisition of data, statistical analysis and interpretation of the results and draft of the manuscript. JW participated in the design of the study, statistical analysis, interpretation of results and critically revised the manuscript. KV participated in the design of the study, statistical analysis, interpretation of results and critically revised the manuscript. All authors have read and approved the final manuscript.

\section{Acknowledgements}

The authors would like to thank all the children who completed the questionnaires, the parents, school principals and the Gauteng Department of Education for giving permission to conduct the study, the students who conducted the interviews, the data capturers and Cornelius Nattey and Vusi Nkosi for their assistance during the data processing stages. The authors would like to thank the University of Pretoria, Tshwane University of Technology, Medical Research Council and the National Research Foundation for funding the study for academic research purposes.

\section{Author details}

${ }^{1}$ Department of Environmental Health, Tshwane University of Technology, Private Bag X680, Pretoria 0001, South Africa. ${ }^{2}$ School of Health Systems and Public Health, Health Sciences Faculty, University of Pretoria, P.O. Box 667, Pretoria 0001, South Africa.
Received: 9 April 2015 Accepted: 21 October 2015

Published online: 26 October 2015

\section{References}

1. Ozdoganoglu T, Songu M. The burden of allergic rhinitis and asthma. Ther Adv Respir Dis. 2012;6:11-23.

2. Skoner DP. Allergic rhinitis: definition, epidemiology, pathophysiology, detection, and diagnoses. J Allergy Clin Immunol. 2001;108:S2-8.

3. Greiner AN, Hellings PW, Rotiroti G, Scadding GK. Allergic rhinitis. Lancet. 2011;378:2112-22

4. Scadding KG. Allergic rhinitis in children. J Paediatr Child Health. 2008;18:323-8.

5. Gerber M, Brignoli R, Canevascini M, Wuthrich B. Epidemiological survey in hay fever patients. Allergy. 1995;50:161-3.

6. Butland BK, Strachan DP, Lewis S, Bynner J, Butler N, Britton J. Investigation into the increase in hay fever and eczema at age 16 observed between the 1958 and 1970 British birth cohorts. BMJ. 1997;315:712-21.

7. Fleming DM, Crombie DL. The prevalence of asthma and hay fever in England and Wales. Brit Med J. 1987;294:279-83.

8. Burr ML, Butland BK, King S, Vaughan-Williams E. Changes in asthma prevalence: two surveys 15 years apart. Arch Dis Child. 1989;64:1452-6.

9. Galassi C, De Sario M, Biggeri A, Bisanti L, Chellini E, Cccone G, et al. Changes in the prevalence of asthma and allergies among children and adolescents in Italy 1994-2002. Pediatrics. 2006;117:34-42.

10. Peñaranda A, Aristizabal G, Garcia E, Vasquez C, Rodriguez-Martinez EC, Satizábal LC. Allergic rhinitis and associated factors in school children from Bogotá, Colombia. Rhinology. 2012;50:122-8.

11. Mandhane SN, Shah JJ, Thennati R. Allergic rhinitis: an update on disease, present treatments and future prospects. Int Immunopharmacol. 2011;11:1646-62

12. Soto-Quiros ME, Silverman KE, Hanson AL, Weiss TS, Celedon CJ. Maternal history, sensitization to allergens, and current wheezing, rhinitis and eczema among children in Costa Rica. Pediatr Pulmonol. 2002;33:237-43. 
13. Brunekreef B, Sunyer J. Asthma, rhinitis and air pollution: is traffic to blame? Eur Respir J. 2003;21:913-5.

14. Janssen N, Brunekreef B, Van Vliet P, Aarts F, Meliefste K, Harssema H, et al. The relationship between air pollution from heavy traffic and allergic sensitization, bronchial hyperresponsiveness, and respiratory symptoms in Dutch schoolchildren. Environ Health Perspect. 2003:111:1512-8.

15. Berman D. Climate change and aeroallergens in South Africa. Curr Opin Allergy Clin Immunol. 2011;24:65-71.

16. Green RJ, Hockman M, Friedman R, Vardas E, Cole P, Halkas A, et al. Allergic rhinitis in South Africa: 2012 guidelines. S Afr Med J. 2012;102:693-6.

17. Green RJ, Hockman M, Friedman MR, Davies M, Mc Donald M, Seedat R, et al. Chronic rhinitis in South Africa: update 2013. S Afr Med J. 2013:103:419-22

18. Zar HJ, Ehrlich RI, Workman L, Weinberg EG. The changing prevalence of asthma, allergic rhinitis and atopic eczema in African adolescents from 1995 to 2002. Pediatr Allergy Immunol. 2007;18:560-5.

19. Scorgie Y, Fischer T, Watson R. Air quality management plan for the Ekurhuleni metropolitan municipality. [www.ekurhuleni.gov.za/465-airquality-management-plan-2005/file [Accessed 01 March 2015].

20. South Africa: Government Notice, Department Environmetal Affairs and Tourism, No.1123, 23 November 2007. Declaration of the Highveld as priority area in terms of Section 18(1) of the National Environmetal Management : Air Quality Act. 2004. Act No. 39 of 2004

21. Asher MI, Keil U, Anderson HR, Beasley R, Crane J, Martinez F, et al. International study of asthma and allergies in childhood (ISAAC): rationale and methods. Eur Respir J. 1995:8:483-91.

22. Gortmaker SL, Hosmer DW, Lemeshow S. Applied logistic regression. Contemporary sociology. 2nd ed. New York: John Wiley and Sons; 1994. p. 159.

23. Ait-Khaled N, Odhiambo J, Pearse N, Adjoh KS, Maesano IA, Benhabyles B, et al. Prevalence of symptoms of asthma, rhinitis and eczema in 13 to 14 year old children in Africa: the International Study of Asthma and Allergies in Childhood Phase III. Allergy. 2007;62:247-58.

24. Tamay Z, Akcay A, Ergin A, Guler N. Effects of dietary habit and risk factors on allergic rhinitis among Turkish adolescents. Int J Pediatr Otorhinolaryngol. 2013;77:1416-23.

25. Sultész M, Katona G, Hirschberg A, Gálffy G. Prevalence and risk factors for allergic rhinitis in primary schoolchildren in Budapest. Int J Pediatr Otorhinolaryngol. 2010;74:503-9.

26. Weiland KS, Mundt AK, Rückmann A, Keil U. Self reported wheezing and allergic rhinitis in childen and traffic density on street of residence. Ann Epidemiol. 1994;4:243-7.

27. Brunekreef B, Stewart AW, Anderson R, Lai CKW, Strachan DP, Pearce N, et al. Self-reported truck traffic on the the street of residence and symptoms of asthma and allergic disease: a global relationship in ISAAC Phase 3. Environ Health Perspect. 2009:117:1791-8.

28. Hwang BF, Jaakkola JJK, Lee YL, Lin YC, Guo LYL. Relation between air pollution and allergic rhinitis in Taiwanese school children. Respir Res. 2006; $7: 23$.

29. World Health Organization. Review of evidence on health aspects of air pollution- REVIHAAP Project. 2013. Technical Report. [http://www.euro. who.int/pubrequest].

30. South Africa. Electronic National Administration Traffic Information System (eNaTIS). Live vehicle population as per the National Traffic Information System. [udated 30 April 2015; cited 2015 Jun 27] available from: http://www.enatis.com.

\section{Submit your next manuscript to BioMed Central and take full advantage of:}

- Convenient online submission

- Thorough peer review

- No space constraints or color figure charges

- Immediate publication on acceptance

- Inclusion in PubMed, CAS, Scopus and Google Scholar

- Research which is freely available for redistribution 